\title{
Behavioral expression of the asymmetry in lobster claws
}

\author{
W. F. ANGERMEIER \\ Marine Behavior Research Station, Lettermullen, Republic of Ireland \\ and University of Cologne, Cologne, Germany
}

\begin{abstract}
Twenty-four lobsters (Homarus gammarus) weighing between 375 and $900 \mathrm{~g}$ were used in a preliminary experiment that was designed to answer questions pertaining to a possible behavioral expression of the asymmetry in lobster claws. When only one side of the food device (either left or right) was baited, all lobsters with the large crusher claw on the left side made more mistakes on the left, and all lobsters with the large crusher claw on the right side made more mistakes on the right. These results are discussed in terms of laterality.
\end{abstract}

There is ample evidence that patterns of behavior are modified as a result of differential experiences affecting genetic predispositions. For the human brain, Corballis and Morgan (1978), for example, have suggested that the two hemispheres mature at different rates, with the left hemisphere probably suppressing the activities of the right. Imprinting (Lorenz, 1945) and "critical periods of development" (Angermeier, 1960; Angermeier \& James, 1961; Angermeier \& Phelps, 1967; Angermeier, Philhour, \& Higgins, 1965) are other examples.

The asymmetry in lobster claws (a large crusher claw and a-usually-smaller and slender cutter claw) also seems to be the result of differential activities of the paired claws during a critical period early in life (Govind, 1989). In a series of fascinating experiments, Govind and Pearce (1986) showed that, when a suitable substrate or appropriate activities are absent, the lobster will develop two cutter claws (paired claws). They further found that rearing with different substrates (e.g., oyster chips, painted chips, mirror, no substrate, etc.), as well as exercise of the claws by handling, leads to claw laterality, which is determined "by the central nervous system through differential reflex activity in the paired claws; the side with the greater activity becomes the crusher, while the contralateral side becomes the cutter' (pp. 468-469).

It is certain that the large crusher claw, innervated only by slow fibers, is used primarily for food collection, whereas the slender cutter claw serves in territorial defense (Govind \& Pearce, 1986). Our own observations support the results of many other investigators: Of 1,440 lobsters caught in traps, 716 had the large crusher claw on the left side of their bodies, 724 on the right. As is

This research was performed at the Marine Behavior Research Station at Lettermullen, Republic of Ireland, and supported by the University of Cologne, Germany. Thanks are due to John Bhaba Jack Connolly for helping procure the animals and Roisin Connolly for her help in gathering the data. Requests for reprints should be sent to the author at the following address: Universität zu Köln, Psychologisches Institut, Zülpicher Str. 47, 5000 Köln 41, Germany. evident, this relationship differs markedly from human handedness.

Pilot experiments with 6 lobsters, 3 each with the large crusher claw on the left and on the right, respectively, showed conclusively that (1) there was no food preference when the bait was mackerel, pollack, or whitefish, when both sides of the food device were baited; (2) there was no preference for one side of the food presentation device (left or right); and (3) there was no difference in latencies or choice of sides between fresh fish and fish that were 1, 2, or 3 days old. Given these results, the question arose whether lobster claw asymmetry might perhaps find its behavioral expression when only one side is baited, thus eliminating part of the sensory input (smell, taste, vision) coming from the other side.

\section{METHOD}

\section{Subjects}

Eighteen European lobsters (Homarus gammarus) were the subjects. The animals were caught in traps off the Western coast of Ireland and then adapted to laboratory conditions in aquaria $(50 \times 30 \times 30 \mathrm{~cm}), 1$ animal to a tank, for a period of 6 days without food.

\section{Apparatus}

The home tanks also served as the test environment. They were equipped with a rock that rested on an oxygen stone, through which the seawater was continuously oxygenated. A piece of wood, cut to fit the upper edges of the aquaria, was fitted with two pieces of wire, to be inserted into the tanks to a depth of $25 \mathrm{~cm}$; thus, pieces of food, attached to the bottom end of the wire, were $5 \mathrm{~cm}$ above the floor of the tank and $3 \mathrm{~cm}$ from the side walls. Only one of the wires was ever baited. By turning the piece of wood around, one could present the food on either the right side or the left, and undue influences of smell or taste were eliminated. (See Figure 1.)

After the adaptation period, a small piece of fish, approximately $1 \mathrm{~g}$ in weight, was presented to the lobster directly in front of its mouth. If the animal did not take the food and eat it within $1 \mathrm{~min}$, or if it pushed the food away from its body, it was eliminated from the experiments. Of the 18 animals remaining after the pilot experiments, 8 were thus eliminated (all females), leaving 5 male animals with the large crusher claw on the left side of the body (LH), and 5 with the large crusher claw on the right $(\mathrm{RH})$.

The experiment was performed between 5 p.m. and 8 p.m. on 8 consecutive days. On each day, the individual animal was presented with 


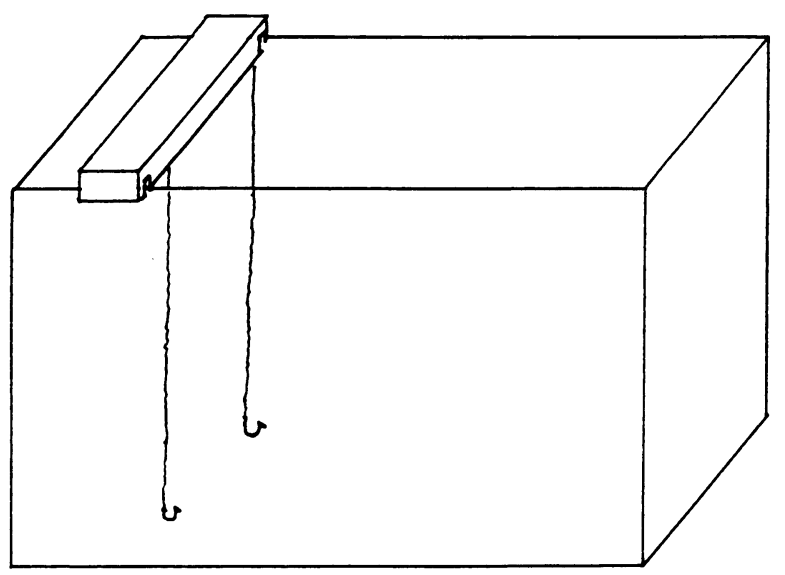

Figure 1. Home and test tank for lobsters, showing food presentation device.

a small piece of fish, approximately $1 \mathrm{~g}$ in weight, on either the left or the right side in the part of the tank that was in front of the lobster's body. Each day, six presentations were made, separated by approximately $5 \mathrm{~min}$. The food was offered according to a random schedule of left-right on each day; however, on each day, three presentations were made on the left side and three on the right.

Latencies and correct or incorrect choices were recorded. A correct choice was made when the animal selected the side that contained the food by holding the wire with one of its claws and pulling the food toward its mouth or by grabbing the food with one of its legs. An incorrect choice was registered when the animal went to the side without foodas above-or did not respond within $300 \mathrm{sec}$. Finally, the level of ambient light was measured (in lux) for all animals during all days of the experiment.

\section{RESULTS}

The percentages of correct and incorrect choices for the $\mathrm{LH}$ and $\mathrm{RH}$ animals are shown in Table 1.

Table 1

Percentages of Correct and Incorrect Choices of Food

\begin{tabular}{ccc}
\hline Subjects & $\begin{array}{c}\text { Correct } \\
\text { Left Side }\end{array}$ & $\begin{array}{c}\text { Correct } \\
\text { Right Side }\end{array}$ \\
\hline LH-1 & 11 & 89 \\
LH-2 & 28 & 72 \\
LH-3 & 45 & 55 \\
LH-4 & 25 & 75 \\
LH-5 & 6 & 94 \\
RH-1 & 89 & 11 \\
RH-2 & 54 & 46 \\
RH-3 & 54 & 46 \\
RH-4 & 67 & 33 \\
RH-5 & 57 & 43 \\
\hline
\end{tabular}

According to Fisher's exact probability test, these results are significant at the .0039 level, denoting significantly more errors when the food is presented on the same side, where the large crusher claw is located.

There were no significant differences in latencies between the left- or right-side presentations of food. There were no significant correlations between the levels of ambient light and errors, correct choices, or latencies observed.

Finally, there were no significant patterns of errors and correct choices during the course of the experiment.

\section{DISCUSSION}

Cautiously interpreted, these results indicate that information pertaining to food (smell, taste, visual clues) is more accurately perceived by the lobster when it comes from the contralateral side of the large crusher claw, which is the primary tool in foraging. The data speak against processes such as random errors, maximizing, or learning. Among the questions that remain are those pertaining to the importance of the antennules, the antennae, and the cutter claw in food-getting behavior. Another question is whether the behavioral principles observed here apply equally well to the functions of the cutter claw, which is used primarily for defense. Are attacks that come from the side, contralateral to the cutter claw, more quickly and accurately met than those from the ipsilateral side?

Using the differential functions of the human brain as an analogy, one could speculate whether the same basic principles of development (Govind, 1989) apply to lobster claw asymmetry. Indeed, is specialization of function the only principle inherent in such asymmetries?

Studies to seek answers to these questions are presently in progress.

\section{REFERENCES}

ANGermeier, W. F. (1960). Some basic aspects of social reinforcements in albino rats. Journal of Comparative \& Physiological Psychology, 53, 364-367.

ANGERMEIER, W. F., \& JAMES, W. T. (1961). The influence of early social-sensory deprivation on the social operant in dogs. Journal of Genetic Psychology, 99, 153-158.

ANGermeier, W. F., \& Phelps, J. B. (1967). The effects of differential early experience upon learning performance and biochemical responses of nonhuman primates (rhesus monkeys) (Tech. Rep. 10). 6571st Aeromedical Research Laboratory, Holloman AF Base, New Mexico.

Angermeier, W. F., Philhour, P., \& Higins, J. (1965). Early experiences and social grouping in fear extinction in rats. Psychological Reports, 16, 1005-1010.

Corballis, M. C., \& Morgan, M. J. (1978). On the biological basis of human laterality. Behavior \& Brain Sciences, 2, 261-336.

Govind, C. K. (1989). Asymmetry in lobster claws. American Scientist, 77, 468-474.

Govind, C. K., \& PeARCE, J. (1986). Differential reflex activity determines claw and closer muscle asymmetry in developing lobsters. Science, 233, 354-356.

LORENZ, K. (1965). Evolution and modification of behavior. Chicago: University of Chicago Press.

(Manuscript received January 9, 1991.) 